\title{
Aliskiren, the first direct renin inhibitor: assessing a role in pediatric hypertension and kidney diseases
}

\author{
Shahid Nadeem • Donald L. Batisky
}

Received: 28 March 2013 / Revised: 20 November 2013 / Accepted: 20 November 2013 / Published online: 14 December 2013

(C) IPNA 2013

\begin{abstract}
This article provides a review of the role of aliskiren, a direct renin inhibitor, in pediatric hypertension and kidney diseases. Among the many mechanisms involved in regulating blood pressure, the renin-angiotensin-aldosterone system (RAAS) plays a major role. Additionally, the RAAS has been identified as a contributing factor to cardiovascular and renal diseases for more than three decades. The potential benefits of inhibiting the RAAS by aliskiren alone or in combination with other RAAS blockers (ACEIs, ARBs) seem to be theoretically promising. However, caution should be exercised in treating children, especially in those with significant chronic kidney disease until there is more evidence regarding the safety and efficacy of this new drug in the pediatric population from ongoing clinical trials.
\end{abstract}

Keywords Aliskiren · Renin · Angiotensin · Hypertension · Blood pressure $\cdot$ Hyperkalemia

\section{Introduction}

Hypertension (HTN) is a worldwide health problem associated with an increased risk for mortality and morbidity from cardiovascular and renal disease [1, 2]. Pediatric HTN remains one of the strongest predictors of adult HTN [3], which significantly increases the cardiovascular mortality risk in adults $[4,5]$. Over the past decade, the prevalence of HTN in the pediatric population has increased in correlation to the rise in childhood overweight and obesity $[4,6,7]$. Although the exact prevalence and incidence of pediatric HTN is unknown, one study estimated the prevalence to be $4.5 \%$ after three separate

S. Nadeem $\cdot$ D. L. Batisky $(\bowtie)$

Children's Healthcare of Atlanta, Emory University School of

Medicine, 2015 Uppergate Drive NE, Atlanta, GA 30322, USA

e-mail: dbatisk@emory.edu screenings were conducted on a group of $>4,000$ children aged 10-19 years [8].

\section{Background: HTN, pre-HTN and staging}

Hypertension is the sustained level of blood pressure (BP) that over time leads to a variety of adverse effects on target organs, such as the heart (left ventricular hypertrophy), the brain and central nervous system and the kidneys. Defined statistically, HTN is when the systolic and/or BP are at or above the 95th percentile for age, gender and stature on at least three occasions. The Fourth Report on the Diagnosis, Evaluation, and Treatment of High Blood Pressure in Children and Adolescents emphasizes better early detection and control of HTH in children and recommends BP screening in children aged $>3$ years who are seen in a medical setting and in younger children under special circumstances that increase the risk for HTN $[9,10]$. This statistical definition of HTN is one that is based on normative distribution of casual office BPs in healthy children and is stratified by age, gender and stature [9].

The BP is measured in the office setting by non-invasive techniques, such as auscultatory and oscillometric methods. Although the auscultatory method is the recommended one for measuring BP, the oscillometric technique may be used due to its ease of performance. However, the BP measurement should be repeated by the auscultatory method if it is elevated according to the oscillometry results [9]. The current practice of clinic-based HP management leads to undertreatment for some patients and overtreatment for others [11]. Even with proper techniques, BP control is misclassified for $>25 \%$ of patients when a single office visit measurement is used [12]. Some patients exhibit "white-coat HTN" (WCH) with elevated BP levels in the medical office but not in other settings, whereas others have "masked HTN" with elevated BP outside the clinical setting but normal in a medical office. 
The 24-h ambulatory blood pressure monitoring (ABPM) method is a useful tool for evaluating children with concerns for HTN and is the only method currently available to reliably identify WCH and masked HTN in children [13]. Using 24-h ABPM as a criterion standard, an average of six BP readings taken at different clinic visits are needed to classify BP control with $80 \%$ accuracy [14]. For most patients, this high number of in-person visits are impractical, and it has become clear from different recent studies that bringing HTN care out of the office and into patients' homes is an approach that works [11, 15]. Nonetheless, widespread adoption of home BP monitoring supported by team care has not occurred in the USA and it is not likely to occur spontaneously [11]. For home BP monitoring to become part of routine practice, major changes to the current system of reimbursement and performance measurement will be needed.

HTN in children is classified by the National High BP Education Program on the basis of a child's BP percentile into normal ( $<$ 90th percentile), pre-HTN (90-94th percentile), stage 1 HTN ( $>95$ th percentile) or stage 2 HTN ( $>99$ th percentile plus 5). Primary HTN, defined by the lack of an underlying causative disorder, is frequently found in children with obesity or a family history of HTN or cardiovascular disease. The worldwide childhood obesity epidemic has had a profound impact on the frequency of HTN and other obesityrelated conditions, with the result that primary HTN should now be viewed as one of the most common health conditions in the young [16]. Secondary HTN is more commonly seen in children than in adults, with the majority of secondary HTN presenting in the pediatric patient group caused by renal or renovascular dysfunction [9].

In children with pre-HTN, actual pharmacologic treatment is controversial. For children with stage 1 primary HTN, the primary treatment to decrease BP is therapeutic lifestyle/ behavior changes, unless there is evidence of target organ damage, such as left ventricular hypertrophy [8]. Therapeutic lifestyle changes include keeping a healthy weight, regular physical activity and dietary modification. Pharmacologic treatment is indicated in secondary HTN, primary stage 2 HTN or if the lifestyle measures prove inadequate [8]. Current recommendations for pharmacologic management of HTN in pediatric patients include the use of angiotensin-converting enzyme inhibitors (ACEIs), angiotensin II receptor blockers (ARBs), $\beta$-adrenergic blockers, calcium channel blockers or diuretics. Although there is documented evidence on the safety and efficacy of diuretics and $\beta$ blockers in pediatric patients with HTN, ACEIs and ARBs are recommended for initial therapy in pediatric patients with concomitant diabetes and microalbuminuria or proteinuria or chronic kidney disease (CKD) [4, 10, 17]. Renin-angiotensin-aldosterone system (RAAS) blockade is also recommended by the European Society of Hypertension as the first line treatment of children with primary HTN associated with obesity/metabolic syndrome as ACEIs and ARBs might induce reduction of insulin resistance and subsequent changes in the lipid profile and in glucose levels [10]. Although the number of available antihypertensive medications is ever growing, selecting the most appropriate agent and effectively treating high BP remains a challenge.

The purpose of this article is to provide a review of the literature on the role of aliskiren, a direct renin inhibitor, in pediatric HTN and kidney diseases. Among the many mechanisms involved in regulating BP, the RAAS is one of the major players. The potential benefits of inhibiting the RAAS, a contributing factor to cardiovascular and renal diseases, have been known for more than three decades [18], and a recent review in Pediatric Nephrology by Silva and Flynn underscores the complexity of this system that is still being elucidated [19]. Four groups of RAAS blockers have been developed, namely, direct renin inhibitors (DRIs), ACEIs, ARBs and aldosterone antagonists.

\section{The RAAS and the role of aliskiren}

The RAAS has an important role in the regulation of arterial BP and volume and electrolyte homeostasis [20] (Fig. 1). Renin, a proteinase enzyme, is secreted by the juxtaglomerular cells of the kidney in response to a decrease in circulating volume and BP. It cleaves the substrate angiotensinogen to form the inactive decapeptide angiotensin I (Ang I), and it is the initial and rate-limiting step in the RAAS cascade [21]. Ang I is then converted to the active octapeptide, Ang II, by the ACE. Ang II interacts with cellular receptors to induce vascular constriction and the release of catecholamines from the adrenal medulla and prejunctional nerve endings. It also promotes aldosterone secretion and sodium reabsorption. In addition, Ang II inhibits renin release, thereby providing negative feedback to the system [18, 22]. Ang II increases vascular resistance and BP at various levels (e.g. vasculature, sympathetic nervous system, cortex and medulla of the adrenal gland).

The RAAS may be blocked at various levels along its pathway (Fig. 1). ARBs act on the RAAS by inhibiting the interaction between Ang II and the angiotensin II type 1 receptor (AT1 receptor). ACE inhibitors block the conversion of Ang I to Ang II and also inhibit the degradation of bradykinin. However, up to $45 \%$ of adult congestive heart failure patients have elevated Ang II levels despite the long-term use of an ACEI [23], possibly reflecting insufficient suppression of ACE due to an inadequate dose of ACEI. However, in optimum ACEI dosing, the most obvious explanation is the existence of alternative enzymes for the formation of Ang II [24]. Non-ACE mediated pathways (e.g., tissue chymase mediated Ang II formation) may become activated when ACE activity is reduced by an ACEI. There are also data suggesting 
Fig. 1 The renin-angiotensinaldosterone system (RAAS). $D R I$ Direct renin inhibitor, $A C E$ angiotensin-converting enzyme, $A C E I$ angiotensin-converting enzyme inhibitor, $A T 1$ receptor angiotensin II type 1 receptor, $A R B$ angiotensin receptor blocker. Modified from Segall et al. [22], used with permission

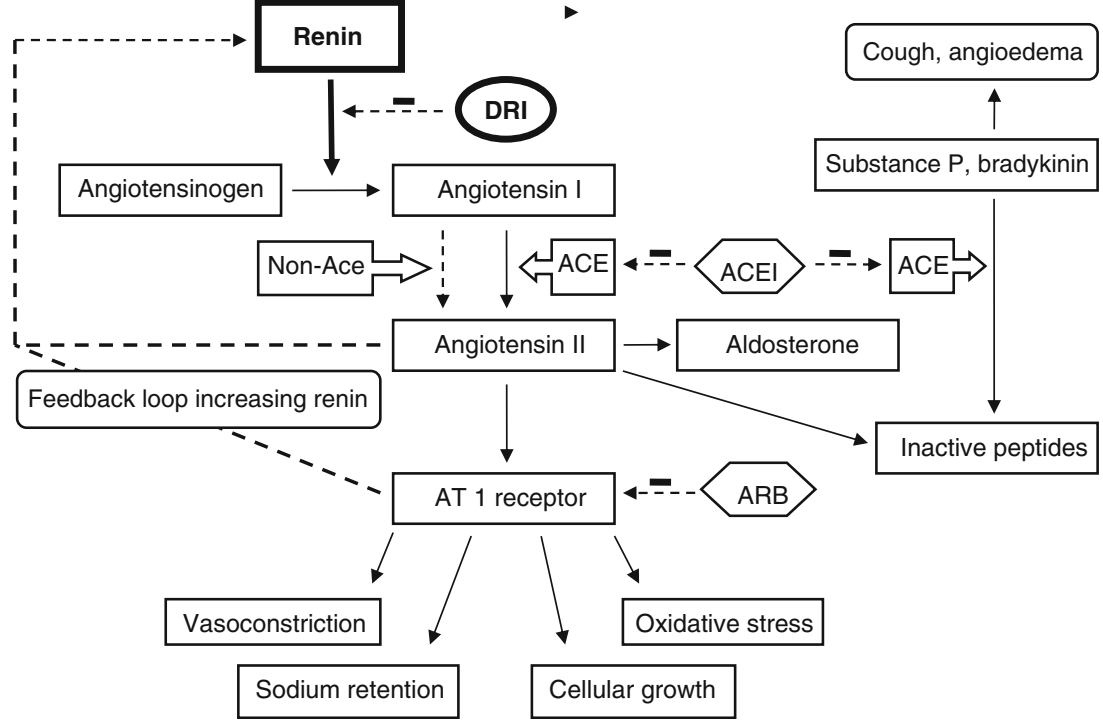

that $30-40 \%$ of Ang II formation influencing the kidney in the healthy human during RAAS activation is formed via renin-dependent, but ACE-independent pathways [25]. Moreover, short- and long-term ACE inhibition results in an accumulation of renin and Ang I-known as ACE escapewhich was also demonstrated in the ESCAPE trial in children with CKD. This mechanism might overcome the ability of an ACEI to effectively suppress ACE activity [26, 27]. A similar mechanism has been discovered for ARBs - the "aldosterone escape"-which leads to normal or even higher than pretreatment levels of aldosterone [28]. Direct renin inhibitors block the RAAS at an earlier stage in the cascade than ACE inhibitors and ARBs and prevent the formation of both Ang I and Ang II by both ACE and non-ACE pathways [22]. This provides the rationale for the use of renin inhibitors for the treatment of HTN and cardiovascular and kidney diseases. Animal studies have revealed that aliskiren has a favorable metabolic profile in subjects with metabolic syndrome by improving glucose tolerance and insulin sensitivity $[29,30]$.

Previous attempts to develop renin inhibitors were limited by poor bioavailability, low renin specificity and high production costs [31]. On March 6, 2007, aliskiren became the first in this new class of antihypertensives known as direct renin inhibitors to receive approval from the U.S. Food and Drug Administration for the treatment of HTN in the adult population. Orally administered aliskiren displays linear pharmacokinetics over the dose range 75-600 $\mathrm{mg}$ in healthy adult volunteers. This drug is excreted primarily unchanged in the feces, with metabolism and renal excretion playing only a minor role, and it shows only moderate protein binding (44$51 \%$ [32]. The mean half-life for aliskiren in healthy adult volunteers is $40 \mathrm{~h}$.

The safety and efficacy of aliskiren has been well defined in both preclinical pharmacological safety studies [33] and phase 2 and 3 clinical studies in adults, involving more than 12,000 adult patients with HTN [34]. Oh and colleagues [35], in a randomized placebo-controlled study involving 672 adults with mild to moderate HTN, demonstrated that all doses of aliskiren in monotherapy $(150,300$, or $600 \mathrm{mg}$ once daily for 8 weeks) gave greater reductions in mean sitting systolic BP and mean sitting diastolic BP [-13.0/-10.3 (150 mg dose), -14.7/-11.1 (300 mg) and $-15.8 /-12.5 \mathrm{mmHg}(600 \mathrm{mg})]$ compared with placebo $(-3.8 /-4.9 \mathrm{mmHg})$. These authors also observed that there was no rebound elevation in BP after treatment withdrawal.

Aliskiren at varying doses $(37.5,75,150,300 \mathrm{mg}$ once daily) was compared with losartan (100 mg once daily) by Stanton and colleagues [36] in a 4-week randomized doubleblind study with 236 mild to moderate hypertensive adults. The results showed dose-dependent reductions in daytime ambulatory systolic BP of -0.4 (37.5 $\mathrm{mg}$ dose), -5.3 $(75 \mathrm{mg}),-8.0(150 \mathrm{mg})$ and $-11.0 \mathrm{mmHg}(300 \mathrm{mg})$. The change in daytime systolic BP with $100 \mathrm{mg}$ losartan was not significantly different from the changes seen with 75,150 and $300 \mathrm{mg}$ aliskiren. All doses of aliskiren also led to significant dose-dependent decreases of plasma renin activity (PRA) of between $-55 \%$ and $-83 \%$, whereas PRA increased by $110 \%$ with losartan.

In a randomized, multicenter, double blind, placebo controlled trial conducted by Gradman et al. [37], 652 adult patients were randomized to receive double-blind treatment with once-daily oral doses of aliskiren $(150,300$, or $600 \mathrm{mg}$ ), irbesartan $150 \mathrm{mg}$ or placebo. The study showed that the antihypertensive effect of aliskiren $150 \mathrm{mg} /$ day was comparable to that of irbesartan $(150 \mathrm{mg} /$ day $)$. However, the treatment with aliskiren 300 and $600 \mathrm{mg}$ daily lowered mean sitting diastolic BP significantly more than irbesartan $150 \mathrm{mg}$ daily. Aliskiren showed safety and tolerability comparable to those of placebo and irbesartan. 


\section{Adverse events associated with RAAS inhibition}

\section{ACE inhibition and ARBs}

Angiotensin-converting enzyme inhibitors and ARBs in monotherapy or in combination therapy have been associated with the development of hyperkalemia, worsening renal function and hypotension due to the effects of RAAS blockade [38, 39]. Patients with additional risk factors for hyperkalemia, such as diabetes and CKD, are at a higher risk for these conditions. However, these are the patients who are most often in dire need of target organ protection by blocking the deleterious effects of Ang II [40]. The other common side-effects of ACEI and ARB treatments (dry cough and angioedema) are thought to be related to the inhibition of bradykinin metabolism. As ARBs do not block the ACE pathway, their use seems to lead to fewer adverse effects related to bradykinin accumulation as compared to ACE inhibitors.

\section{Direct renin inhibition}

Direct renin inhibitors in theory seem to share the same adverse effects as other RAAS blockers. However, based on their pooled analysis of more than 7,000 adult patients in five placebo-controlled trials, Weir et al. [34] reported that the overall incidence of adverse events (AEs) associated with 68 weeks of aliskiren monotherapy (75-600 mg once daily) was similar to that of placebo. The safety and tolerability of DRIs were affirmed with another pooled study in adult women involving 1,527 patients in five placebo-controlled trials: the adverse effect profile was same in both groups [41]. In these studies, the most common AEs thought to be related to aliskiren treatment were headache, diarrhea and fatigue. Combination therapy with aliskiren $150 \mathrm{mg}$ or $300 \mathrm{mg}$ once daily and another antihypertensive agent, including an ACEI or an ARB, did not greatly affect the incidence or type of AEs associated with the respective monotherapy [34]. The rate of cough for patients with HTN and diabetes who were treated with ramipril alone was $4.7 \%$, but it was $1.5 \%$ for those who treated with the combination of aliskiren and ramipril. The occurrence of hyperkalemia was similar in patients with placebo $(0.6 \%)$ and patients with aliskiren with different dosing groups (0.6-1\%), except for the group receiving $600 \mathrm{mg}$ who did not exhibit hyperkalemia. The rate of hyperkalemia was similar in patients with aliskiren monotherapy, placebo and the combination of aliskiren + hydrochlorothiazide (HCTZ), valsartan or amlodipine. However, the rate of hyperkalemia was higher, although transient when aliskiren was combined with ramipril $(5.5 \%)$ than in those treated with ramipril alone $(2.6 \%)$. Similarly, there were no notable changes in kidney function assessed by serum creatinine concentration or blood urea nitrogen in patients with the combination of aliskiren +
HCTZ, amlodipine or valsartan compared with the respective monotherapy.

The pharmacokinetics, safety and tolerability of aliskiren have also been assessed in adult patients with varying degrees of renal [42] or hepatic impairment [43] and compared with those parameters in healthy subjects. The results of these studies led the authors to conclude that adjustment of the aliskiren dose is not required in patients with renal or hepatic impairment. However, according to the package insert, it is recommended to exercise caution in patients treated with aliskiren who have greater than moderate renal dysfunction, a history of dialysis therapy, nephrotic syndrome or renovascular HTN due to the paucity of data in these patients and the potential for other agents affecting the RAAS to increase serum creatinine and blood urea nitrogen levels.

RAAS inhibition has also a proven benefit in reducing proteinuria [44], one of the most important risk factors for the progression of CKD and cardiovascular events [45]. RAAS blockade using double therapy has been reported to be more effective than that with monotherapy [46]. The data on proteinuria reduction in adult CKD patients receiving treatment with aliskiren are promising [47]. Patients with HTN and diabetes, with and without microalbuminuria, have gained renoprotective benefits through inhibition of the RAAS by treatment with ACE inhibitors or ARBs [48]. The authors of the AVOID study [49] found that treatment with $300 \mathrm{mg}$ of aliskiren daily, as compared with placebo, reduced the mean urinary albumin-to-creatinine ratio by $20 \%$, with a reduction of $\geq 50 \%$ in $24.7 \%$ of the patients who received aliskiren as compared with $12.5 \%$ of those who received placebo. Although dual RAAS blockade theoretically/ physiologically seems to be a promising therapy in HTN and CKD, no data from large adult trials substantiate such a benefit [50]. The results of the ALTITIUDE study in adults clearly show that dual blockade with aliskiren + ACEI or ARB has no demonstrable clinical advantage and may be harmful in type 2 diabetes patients with CKD [50]. Similar to the ALTITUDE results, other studies in adults have also found that dual RAAS blockade causes such AEs as hypotension, hyperkalemia and worsening of renal function [51, 52]. As a result, in December 2011, Novartis International AG (Basel, Switzerland) had to halt a clinical trial of aliskiren after discovering increased incidence of nonfatal stroke, renal complications, hyperkalemia and hypotension in patients with diabetes and renal impairment (ALTITUDE Trial).

There is paucity of data on the safety, efficacy and pharmacokinetics (PK) of aliskiren in the pediatric population, and only few studies in the literature, to our knowledge, have discussed these in children. According to one prospective, 8day, randomized, multi-dose study involving five countries, the use of once-daily dose of aliskiren at 2 and $6 \mathrm{mg} / \mathrm{kg}$ was well tolerated in pediatric patients with HTN [17]. The PK parameters of aliskiren in pediatric patients aged 6-17 years 
are consistent with those observed in the adult population. Clinically meaningful BP reductions were observed with both doses of aliskiren: in the 6- to 11-year-old patients the overall mean reduction from baseline to the end of treatment was $-6.1 /-0.8 \mathrm{mmHg}$ ( 2 and $6 \mathrm{mg} / \mathrm{kg}$, respectively) and in the 12 - to 17 -year-old patients it was $-7.7 /-5.6 \mathrm{mmHg}$. Only three patients $(7.7 \%)$ had AEs that were suspected to be related to the study drug (nausea in 2 patients, headache in 1 patient, diarrhea in 1 patient). There were no AEs or abnormal laboratory values for potassium, creatinine or blood urea nitrogen leading to discontinuation from the study. Aliskiren treatment also resulted in substantial decrease in PRA.

Few case series have also retrospectively reviewed the safety and efficacy of aliskiren when used in combination with other RAAS blockers. In one case series, aliskiren was used in combination with losartan \pm ACEIs in four patients (aged 5-18 years) with varying degree of CKD and proteinuria [53]. The authors retrospectively reviewed the medical records of these patients and found that aliskiren was added to losartan \pm ACEI (two patients were also on ACEI, so triple RAAS blockade) for the refractory proteinuria after insufficient response with ARBs \pm ACEIs. Although there was a remarkable reduction in proteinuria (at least $>45 \%$ ), significant side-effects in three of the patients were noted. Aliskiren was subsequently discontinued in two of these latter patients due to hyperkalemia and worsening of renal function, and one patient had the dose changed due to symptomatic hypotension. In the two patients withdrawn from aliskiren treatment, the creatinine level returned to baseline after discontinuation of aliskiren in one patient, and the other patient, with moderate CKD (glomerular filtration rate $32 \mathrm{~mL} / \mathrm{min} / 1.72 \mathrm{~m}^{2}$ ), had acute worsening of renal function and required hemodialysis 3.5 weeks later. The other case series is an e-mail survey of the PEDHTN and PEDNEPH list which identified ten patients with off-label use of aliskiren [54] for the treatment of HTN and/or proteinuria. Hyperkalemia, angioedema and hypotension were the major side-effects. These limited data suggest that aliskiren should be used with caution, especially when used in combination with other blockers of the RAAS axis.

\section{Pediatric trials}

Clinical trials are currently being conducted by Novartis International AG. These include a prospective double-blinded, randomized placebo-controlled trial of aliskiren in pediatric patients with mild to moderate HTN (CSPP100A2365) that is designed to assess the efficacy and safety of aliskiren in the pediatric population. Other trials include a multicenter, doubleblind, randomized, 52-week extension study to evaluate the long-term safety, tolerability and efficacy of aliskiren compared to enalapril in pediatric hypertensive patients aged 6-17 years (CSPP100A2365E1) and a multicenter, 52- to 104-week extension study to evaluate the long-term growth and development of pediatric hypertensive patients aged 6-17 years treated previously with aliskiren (CSPP100A2365E2).

\section{Conclusion}

Although data from adult studies on the safety and efficacy of aliskiren seems to be very promising, caution should be exercised with its use, especially in combination with other RAAS blockers, until further data are available on its pharmacokinetics, safety and efficacy in the pediatric population from ongoing clinical trials.

\section{Questions (answers are provided following the Reference list)}

1. The mechanism of action of aliskiren to improve BP control includes:

a. Direct action on peripheral vasculature

b. Centrally-mediated vasodilatation

c. Decreased formation of angiotensin I and angiotensin II

d. Effects on calcium channels

2. Side-effects that may be anticipated in the use of aliskiren include:
a. Cough
b. Angioedema
c. Elevated transaminases
d. Hyperkalemia

3. The true statement about pediatric HTN is:

a. Aliskiren has the safest antihypertensive medication side-effect profile published to date.

b. Pediatric HTN is generally defined statistically as a sustained level of BP that is consistently $>95$ th percentile for age, gender and stature.

c. All pediatric patients diagnosed with HTN must be managed with antihypertensive medications as soon as the diagnosis is confirmed.

d. Children will likely outgrow HTN by the time they finish puberty.

4. Before the development of aliskiren, reasons that limited availability of compounds that act as a direct renin inhibitors included all but:

a. Serious side effect profiles.

b. Poor bioavailability.

c. High production costs.

d. Low renin specificity. 
5. A true statement about renin is:

a. It is secreted by the liver when there is inflammation.

b. It cleaves the substrate angiotensinogen to form angiotensin I.

c. It is produced by the kidney only in CKD stage 4 or higher.

d. It is produced by osteoblasts.

6. The antihypertensive classes that may influence the RAAS include all but:
a. Angiotensin-converting enzyme inhibitors
b. Angiotensin receptor blockers
c. Beta blockers
d. Centrally acting agents
e. Aldosterone inhibitors

\section{References}

1. Erlingsdottir A, Indridason OS, Thorvaldsson O, Edvardsson VO (2010) Blood pressure in children and target-organ damage later in life. Pediatr Nephrol 25:323-328

2. Kearney PM, Whelton M, Reynolds K, Muntner P, Whelton PK, He J (2005) Global burden of hypertension: analysis of worldwide data. Lancet 365:217-223

3. Bao W, Threefoot SA, Srinivasan SR, Berenson GS (1995) Essential hypertension predicted by tracking of elevated blood pressure from childhood to adulthood: the Bogalusa heart study. Am J Hypertens 8: 657-665

4. Chobanian AV, Bakris GL, Black HR, Cushman WC, Green LA, Izzo JL Jr, Jones DW, Materson BJ, Oparil S, Wright JT Jr, Roccella EJ, Joint National Committee on Prevention, Detection, Evaluation, and Treatment of High Blood Pressure. National Heart, Lung, and Blood Institute; National High Blood Pressure Education Program Coordinating Committee (2003) Seventh report of the joint national committee on prevention, detection, evaluation, and treatment of high blood pressure. Hypertension 42:1206-1252

5. Lewington S, Clarke R, Qizilbash N, Peto R, Collins R, Prospective Studies Collaboration (2002) Age-specific relevance of usual blood pressure to vascular mortality: a meta-analysis of individual data for one million adults in 61 prospective studies. Lancet 360:1903-1913, Erratum in: Lancet. 2003 361:1060

6. Din-Dzietham R, Liu Y, Bielo MV, Shamsa F (2007) High blood pressure trends in children and adolescents in national surveys, 1963 to 2002. Circulation 116:1488-1496

7. Muntner P, He J, Cutler JA, Wildman RP, Whelton PK (2004) Trends in blood pressure among children and adolescents. JAMA 291:21072113

8. Sorof JM, Lai D, Turner J, Poffenbarger T, Portman RJ (2004) Overweight, ethnicity, and the prevalence of hypertension in schoolaged children. Pediatrics 113(3 Pt 1):475-482

9. National High Blood Pressure Education Program Working Group on High Blood Pressure in Children and Adolescents (2004) The fourth report on the diagnosis, evaluation, and treatment of high blood pressure in children and adolescents. Pediatrics 114[2 Suppl 4th Report]:555-576

10. Lurbe E, Cifkova R, Cruickshank JK, Dillon MJ, Ferreira I, Invitti C, Kuznetsova T, Laurent S, Mancia G, Morales-Olivas F, Rascher W, Redon J, Schaefer F, Seeman T, Stergiou G, Wühl E, Zanchetti A,
Sociedad Europea de Hipertensión (2010) [Management of high blood pressure in children and adolescents: recommendations of the European society of hypertension]. An Pediatr (Barc) 73(51):1-28 (in Spanish)

11. Magid DJ, Green BB (2013) Home blood pressure monitoring: take it to the bank. JAMA $310: 40-41$

12. Fishman PA, Anderson ML, Cook AJ, Ralston JD, Catz SL, Carlson J, Larson EB, Green BB (2011) Accuracy of blood pressure measurements reported in an electronic medical record during routine primary care visits. J Clin Hypertens (Greenwich) $13: 821-828$

13. Chaudhuri A (2013) Pediatric ambulatory blood pressure monitoring: diagnosis of hypertension. Pediatr Nephrol 28:995-999

14. Powers BJ, Olsen MK, Smith VA, Woolson RF, Bosworth HB, Oddone EZ (2011) Measuring blood pressure for decision making and quality reporting: where and how many measures? Ann Intern Med 154:781-788

15. Margolis KL, Asche SE, Bergdall AR, Dehmer SP, Groen SE, Kadrmas HM, Kerby TJ, Klotzle KJ, Maciosek MV, Michels RD, O'Connor PJ, Pritchard RA, Sekenski JL, Sperl-Hillen JM, Trower NK (2013) Effect of home blood pressure telemonitoring and pharmacist management on blood pressure control: a cluster randomized clinical trial. JAMA 310:46-56

16. Flynn J (2013) The changing face of pediatric hypertension in the era of the childhood obesity epidemic. Pediatr Nephrol 28:10591066

17. Sullivan JE, Keefe D, Zhou Y, Satlin L, Fang H, Yan JH (2013) Pharmacokinetics, safety profile, and efficacy of aliskiren in pediatric patients with hypertension. Clin Pediatr (Phila) 52:599-607

18. Azizi M, Webb R, Nussberger J, Hollenberg NK (2006) Renin inhibition with aliskiren: where are we now, and where are we going? J Hypertens 24:243-256

19. Simões E, Silva AC, Flynn JT (2012) The renin-angiotensin-aldosterone system in 2011: role in hypertension and chronic kidney disease. Pediatr Nephrol 27:1835-1845

20. Skeggs LT, Dorer FE, Kahn JR, Lentz KE, Levine M (1976) The biochemistry of the renin-angiotensin system and its role in hypertension. Am J Med 60:737-748

21. Skeggs LT Jr, Kahn JR, Lentz K, Shumway NP (1957) The preparation, purification, and amino acid sequence of a polypeptide renin substrate. J Exp Med 106:439-453

22. Segall L, Covic A, Goldsmith DJ (2007) Direct renin inhibitors: the dawn of a new era, or just a variation on a theme? Nephrol Dial Transplant 22:2435-2439

23. van de Wal RM, Plokker HW, Lok DJ, Boomsma F, van der Horst FA, van Veldhuisen DJ, van Gilst WH, Voors AA (2006) Determinants of increased angiotensin II levels in severe chronic heart failure patients despite ACE inhibition. Int J Cardiol 106:367372

24. Ihara M, Urata H, Kinoshita A, Suzumiya J, Sasaguri M, Kikuchi M, Ideishi M, Arakawa K (1999) Increased chymase-dependent angiotensin II formation in human atherosclerotic aorta. Hypertension 33: 1399-1405

25. Hollenberg NK (1999) Pharmacologic interruption of the reninangiotensin system and the kidney: differential responses to angiotensin-converting enzyme and renin inhibition. J Am Soc Nephrol 10[Suppl 11]:S239-S242

26. ESCAPE Trial Group, Wühl E, Trivelli A, Picca S, Litwin M, PecoAntic A, Zurowska A, Testa S, Jankauskiene A, Emre S, CaldasAfonso A, Anarat A, Niaudet P, Mir S, Bakkaloglu A, Enke B, Montini G, Wingen AM, Sallay P, Jeck N, Berg U, Caliskan S, Wygoda S, Hohbach-Hohenfellner K, Dusek J, Urasinski T, Arbeiter K, Neuhaus T, Gellermann J, Drozdz D, Fischbach M, Möller K, Wigger M, Peruzzi L, Mehls O, Schaefer F (2009) Strict blood-pressure control and progression of renal failure in children. $\mathrm{N}$ Engl J Med 361:1639-1650 
27. Athyros VG, Mikhailidis DP, Kakafika AI, Tziomalos K, Karagiannis A (2007) Angiotensin II reactivation and aldosterone escape phenomena in renin-angiotensin-aldosterone system blockade: is oral renin inhibition the solution? Expert Opin Pharmacother 8:529-535

28. McKelvie RS, Yusuf S, Pericak D, Avezum A, Burns RJ, Probstfield J, Tsuyuki RT, White M, Rouleau J, Latini R, Maggioni A, Young J, Pogue J, The RESOLVD Pilot Study Investigators (1999) Comparison of candesartan, enalapril, and their combination in congestive heart failure: randomized evaluation of strategies for left ventricular dysfunction (RESOLVD) pilot study. Circulation 100:1056-1064

29. Marchionne EM, Diamond-Stanic MK, Prasonnarong M, Henriksen EJ (2012) Chronic renin inhibition with aliskiren improves glucose tolerance, insulin sensitivity, and skeletal muscle glucose transport activity in obese Zucker rats. Am J Physiol Regul Integr Comp Physiol 302:R137-R142

30. Chou CL, Lai YH, Lin TY, Lee TJ, Fang TC (2011) Aliskiren prevents and ameliorates metabolic syndrome in fructose-fed rats. Arch Med Sci 7:882-888

31. Atlas SA (2007) The renin-angiotensin aldosterone system: pathophysiological role and pharmacologic inhibition. J Manag Care Pharm 13[8 Suppl B]:9-20

32. Zhao C, Vaidyanathan S, Yeh CM, Maboudian M, Armin Dieterich H (2006) Aliskiren exhibits similar pharmacokinetics in healthy volunteers and patients with type 2 diabetes mellitus. Clin Pharmacokinet 45:1125-1134

33. Kelly DJ, Zhang Y, Moe G, Naik G, Gilbert RE (2007) Aliskiren, a novel renin inhibitor, is renoprotective in a model of advanced diabetic nephropathy in rats. Diabetologia 50:2398-2404

34. Weir MR, Bush C, Anderson DR, Zhang J, Keefe D, Satlin A (2007) Antihypertensive efficacy, safety, and tolerability of the oral direct renin inhibitor aliskiren in patients with hypertension: a pooled analysis. J Am Soc Hypertens 1:264-277

35. Oh BH (2007) Aliskiren, the first in a new class of direct renin inhibitors for hypertension: present and future perspectives. Expert Opin Pharmacother 8:2839-2849

36. Stanton A, Jensen C, Nussberger J, O’Brien E (2003) Blood pressure lowering in essential hypertension with an oral renin inhibitor, aliskiren. Hypertension 42:1137-1143

37. Gradman AH, Schmieder RE, Lins RL, Nussberger J, Chiang Y, Bedigian MP (2005) Aliskiren, a novel orally effective renin inhibitor, provides dose-dependent antihypertensive efficacy and placebolike tolerability in hypertensive patients. Circulation 111:1012-1018

38. Phillips CO, Kashani A, Ko DK, Francis G, Krumholz HM (2007) Adverse effects of combination angiotensin II receptor blockers plus angiotensin-converting enzyme inhibitors for left ventricular dysfunction: a quantitative review of data from randomized clinical trials. Arch Intern Med 167:1930-1936

39. Düsing R, Sellers F (2009) ACE inhibitors, angiotensin receptor blockers and direct renin inhibitors in combination: a review of their role after the ONTARGET trial. Curr Med Res Opin 25:2287-2301

40. Rastogi A, Rashid M, Wright RF (2011) Reducing cardiorenal risk through combination therapy with a direct renin inhibitor. J Clin Hypertens 13:848-855

41. Gradman AH, Weir MR, Wright M, Bush CA, Keefe DL (2010) Efficacy, safety and tolerability of aliskiren, a direct renin inhibitor, in women with hypertension: a pooled analysis of eight studies. J Hum Hypertens 24:721-729

42. Vaidyanathan S, Bigler H, Yeh C, Bizot MN, Dieterich HA, Howard D, Dole WP (2007) Pharmacokinetics of the oral direct renin inhibitor aliskiren alone and in combination with irbesartan in renal impairment. Clin Pharmacokinet 46:661-675
43. Vaidyanathan S, Warren V, Yeh C, Bizot MN, Dieterich HA, Dole WP (2007) Pharmacokinetics, safety, and tolerability of the oral renin inhibitor aliskiren in patients with hepatic impairment. J Clin Pharmacol 47:192-200

44. Bhattacharjee R, Filler G (2002) Additive antiproteinuric effect of ACE inhibitor and losartan in IgA nephropathy. Pediatr Nephrol 17: 302-304

45. Toto RD (2010) Aldosterone blockade in chronic kidney disease: can it improve outcome? Curr Opin Nephrol Hypertens 19:444-449

46. Jacobsen P, Andersen S, Jensen BR, Parving HH (2003) Additive effect of ACE inhibition and angiotensin II receptor blockade in type I diabetic patients with diabetic nephropathy. J Am Soc Nephrol 14: 992-999

47. Persson F, Rossing P, Reinhard H, Juhl T, Stehouwer CD, Schalkwijk C, Danser AH, Boomsma F, Frandsen E, Parving HH (2009) Renal effects of aliskiren compared with and in combination with irbesartan in patients with type 2 diabetes, hypertension, and albuminuria. Diabetes Care 32:1873-1879

48. Ruggenenti P, Fassi A, Ilieva AP, Bruno S, Iliev IP, Brusegan V, Rubis N, Gherardi G, Arnoldi F, Ganeva M, Ene-Iordache B, Gaspari F, Perna A, Bossi A, Trevisan R, Dodesini AR, Remuzzi G, Bergamo Nephrologic Diabetes Complications Trial (BENEDICT) Investigators (2004) Preventing microalbuminuria in type 2 diabetes. N Engl J Med 351:1941-1951

49. Riche DM, Minor DS, Holdiness AS, East HE (2009) An issue of dependence: implications from the Aliskiren in the Evaluation of Proteinuria in Diabetes (AVOID) trial. J Clin Hypertens 11:89-93

50. de Leeuw PW (2013) ACP Journal Club. Aliskiren increased adverse events in patients with diabetes and kidney disease who were receiving ACE inhibitors or ARBs. Ann Intern Med 158:JC7

51. Harel Z, Gilbert C, Wald R, Bell C, Perl J, Juurlink D, Beyene J, Shah PS (2012) The effect of combination treatment with aliskiren and blockers of the renin-angiotensin system on hyperkalaemia and acute kidney injury: systematic review and meta-analysis. BMJ 344:e42

52. Mann JF, Schmieder RE, McQueen M, Dyal L, Schumacher H, Pogue J, Wang X, Maggioni A, Budaj A, Chaithiraphan S, Dickstein K, Keltai M, Metsärinne K, Oto A, Parkhomenko A, Piegas LS, Svendsen TL, Teo KK, Yusuf S, ONTARGET investigators (2008) Renal outcomes with telmisartan, ramipril, or both, in people at high vascular risk (the ONTARGET study): a multicentre, randomised, double-blind, controlled trial. Lancet 372 : $547-553$

53. Kelland EE, McAuley LM, Filler G (2011) Are we ready to use aliskiren in children? Pediatr Nephrol 26:473-477

54. Flynn J (2011) Not ready for prime time: aliskiren for treatment of hypertension or proteinuria in children. Pediatr Nephrol 26: 491-492

\section{Answers:}

1. C

2. D

3. B

4. A

5. B

6. D 